\title{
Surgical excision of a residual cyst in a patient with previous history of jaw osteonecrosis associated with oral bisphosphonate: A case report
}

\begin{abstract}
- Ana Carolina Uchoa Vasconcelos Post-Graduate Program, Dental College, Federal University of Pelotas, Rio Grande do Sul, Brazil • Wâneza Dias Borges Post-Graduate Program, Dental College, Pontifical Catholic University of Rio Grande do Sul, Brazil • Cláiton Heitz Post-Graduate Program, Dental College, Pontifical Catholic University of Rio Grande do Sul, Brazil • Fernanda Gonçalves Salum Post-Graduate Program, Dental College, Pontifical Catholic University of Rio Grande do Sul, Brazil • Maria Antonia Zancanaro de Figueiredo Post-Graduate Program, Dental College, Pontifical Catholic University of Rio Grande do Sul, Brazil • Gustavo Giacomelli Nascimento Post-Graduate Program, Dental College, Federal University of Pelotas, Rio Grande do Sul, Brazil • Aline Adelaide Paz da Silva Duarte Post-Graduate Program, Dental College, Pontifical Catholic University of Rio Grande do Sul, Brazil • Karen Cherubini Post-Graduate Program, Dental College, Pontifical Catholic University of Rio Grande do Sul, Brazil
\end{abstract}

ABSTRACT | Residual cyst is an inflammatory odontogenic cyst resultant from pulp necrosis, where the tooth has already been removed. Bisphosphonates are drugs used in the prevention and treatment of bone metabolism diseases with intense resorption activity, and they have been associated with osteonecrosis of the jaws, an important side effect. The aim of this study was to report a successful surgical treatment of a residual cyst in a patient who had previously developed jaw osteonecrosis associated with sodium alendronate use. We emphasize here the importance of safe preoperative procedures when approaching these patients.

DESCRIPTORS | Bisphosphonates; Osteonecrosis; Cysts.

RESUMO | Excisão cirúrgica de cisto residual em um paciente com história prévia de osteonecrose associada ao uso de bisfosfonato: um relato de caso • Cisto residual é uma lesão odontogênica inflamatória resultante de necrose pulpar, em local de extração prévia. Os bisfosfonatos são medicamentos usados na prevenção e tratamento de doenças caracterizadas por excessiva reabsorção óssea, e que têm sido associados com osteonecrose dos maxilares, um importante efeito colateral. O objetivo deste estudo foi relatar um tratamento cirúrgico com sucesso de um cisto residual em um paciente com histórico de osteonecrose mandibular associada ao uso de alendronato de sódio. Cauteloso manejo deve ser creditado quando necessários procedimentos cirúrgicos em tais grupos de pacientes.

DESCRITORES | Bisfosfonatos; Osteonecrose; Cistos.

CORRESPONDING AUTHOR | • Ana Carolina Uchoa Vasconcelos Serviço de Patologia Bucal, Universidade Federal de Pelotas • Rua Gonçalves Chaves, 457, sala 607, Centro Pelotas, RS, Brazil • $\mathbf{9 6 0 1 5}$ 560 E-mail: carolinauv@gmail.com

- Received Apr 30, 2015 • Accepted Jun 07, 2015

- Dol http://dx.doi.org/10.11606/issn.2357-8041.clrd.2015.97658 


\section{INTRODUCTION}

Bisphosphonates are a group of drugs that have been used in the management of metabolic and oncologic diseases characterized by an increase of osteoclastic activity. In the clinical setting, these agents are available for oral and intravenous (IV) administration. ${ }^{1}$ The first one is primarily used for treatment of osteoporosis, reducing the risk of vertebral and non-vertebral fractures. When administered by IV route, they are indicated for stabilization of bone metastasis of solid tumors, treatment of bone resorption defects in multiple myeloma, correction of hypercalcemia and in the management of Paget's disease and fibrous dysplasia. ${ }^{1}$ Additionally, in 2007, Food and Drug Administration (FDA) approved parenteral administration of zoledronic acid for management of osteoporosis. ${ }^{1}$

Adverse effects of bisphosphonate therapy are intimately related to type, frequency and route of drug administration. Firstly described in 2003, bisphosphonate-related osteonecrosis of the jaws (BRONJ), now called medication-related osteonecrosis of the jaw (MRONJ) is an important side effect whose etiopathogenesis is not completely known. ${ }^{2}$ It was estimated that up to $12 \%$ of patients treated with IV bisphosphonates for cancer could develop MRONJ. ${ }^{1}$ Among patients taking oral bisphosphonates, this condition was estimated at $0.1 \% .^{3}$

Clinically, MRONJ is defined as an area of exposed bone in the maxillofacial region that persists for at least eight weeks in a patient who is receiving or has been exposed to a bisphosphonate and has not had radiation therapy to the craniofacial region. ${ }^{3}$ Radiographic features cannot be distinguished from periapical lesions, osteomyelitis, primary or metastatic bone disease. ${ }^{4}$ Microscopically, non-vital bone tissue, chronic inflammatory infiltrate, bacteria colonization consistent with Actinomyces sp, and absence of osteoclasts are observed.
Furthermore, intertrabecular fibrosis and inflammatory infiltrate within bone marrow spaces can also be noted. 5

The major goal of management for patients who have MRONJ is to preserve the quality of life through controlling pain, managing infection, and preventing the development of new areas of necrosis. ${ }^{4}$ Laboratory tests that can provide the intensity of collagen degradation, such as carboxy-terminal collagen crosslinks (CTX), even nonspecific, can provide predictive values in cases that need maxillofacial surgery. ${ }^{6}$

The aim of this study is to report a successful surgical treatment of a maxillary residual cyst in a patient who had previously developed BRONJ associated with alendronate use.

\section{CASE REPORT}

A 73-year-old female patient presented with a MRONJ in right mandible two months after extraction of right mandibular first and second premolars. At that time, serum CTX was $20 \mathrm{pg} / \mathrm{mL}$, alendronate therapy was withdrawn, for three years, by the patient's physician, and medical treatment for MRONJ was started. One year after this, the lesion was completely healed. Treatment consisted of oral penicillin and mouthrinse with antimicrobial solutions (erythromycin, chlorhexidine and hydrogen peroxide). During routine examinations, three years after extractions, panoramic radiograph revealed a well-circumscribed and radiolucent lesion, measuring $2.3 \times 1.7 \mathrm{~cm}$, in the posterior left side of maxilla (Figure 1) without any clinical sign and compatible with a residual cyst. Computed tomography showed a well demarcated, unilocular and hypodense mass in the posterior left side of maxilla, measuring $1.3 \times 1.1 \mathrm{~cm}$ (Figure 2). At this point, patient was not using bisphosphonate anymore (for about six months) but CTX was still low. 


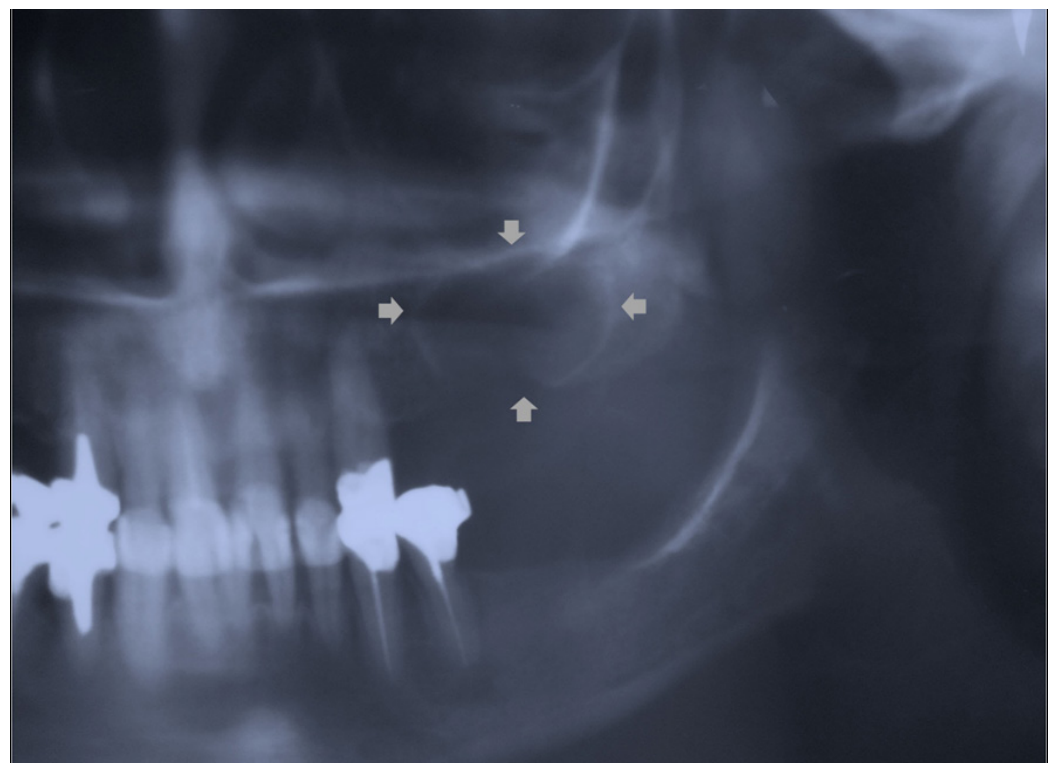

Figure 1 | Initial panoramic radiography.

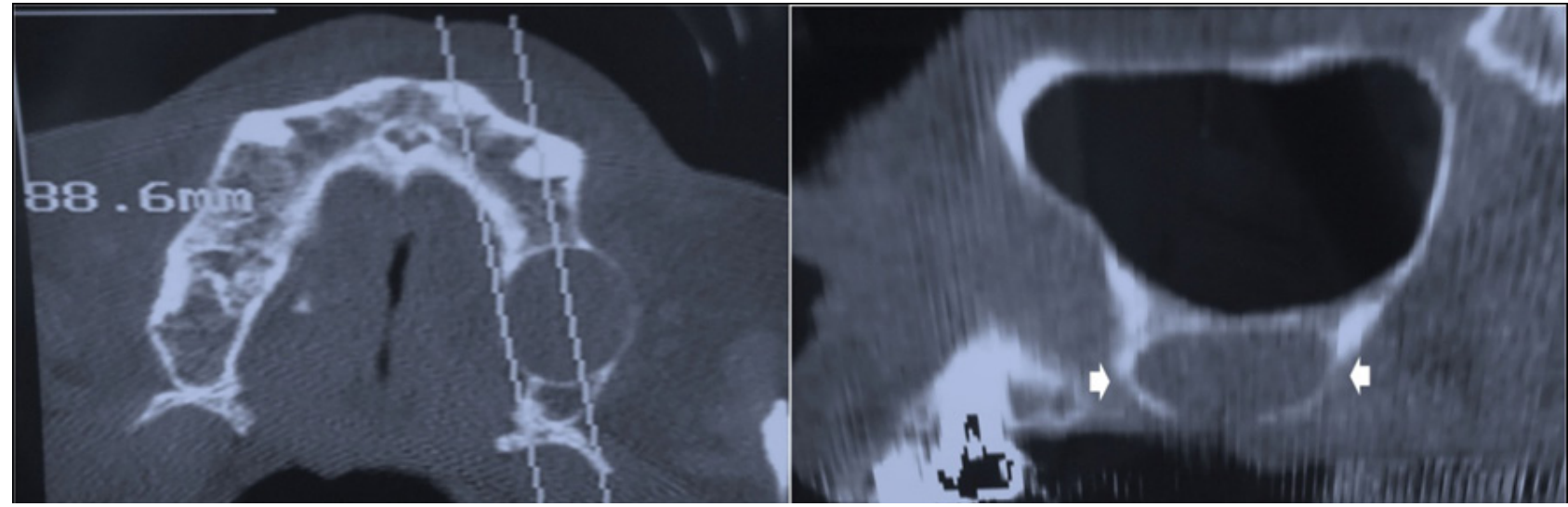

Figure 2 | Initial computed tomography.

Surgical excision of the cystic lesion was indicated only when CTX improvement was observed. Hematologic exams including complete blood count, prothrombin time, activated thromboplastin time, aspartate transaminase (AST), alanine transaminase (ALT), urea and fasting blood glucose (FBG) showed normal results. Also, CTX was requested again, and the result was $430 \mathrm{pg} / \mathrm{mL}$, which would represent minimal risk for MRONJ, according to Marx. ${ }^{6}$

During surgical procedure, intra- and extra-oral antisepsis was made with chlorhexidine, and local anesthesia was performed with mepivacaine. Tissue incision and divulsion were performed on a minimally traumatic technique. A Lucas curette was used to displace the cyst capsule and, after lesion excision, the affected site was irrigated with physiological saline solution, with posterior osteoplasty and continuous suture with nylon (4o). After surgical procedure, the patient received a prescription of oral clindamycin, 300mg, for 7 days; oral nimesulide, 100mg, for 3 days, sublingual trometamol, $10 \mathrm{mg}$, for 3 days and mouthrinse with $0.12 \%$ chlorhexidine.

Histopathological examination revealed an inflammatory cyst, lined with stratified squamous epithelium, which showed hydropic degeneration, spongiosis and hyperplastic areas. The 
connective tissue was fibrous with small caliber blood vessels, presenting predominantly mononuclear inflammatory infiltrate (Figure 3). These characteristics confirmed the radiographic diagnosis of residual cyst. Follow-up appointments were booked weekly in the first two months and

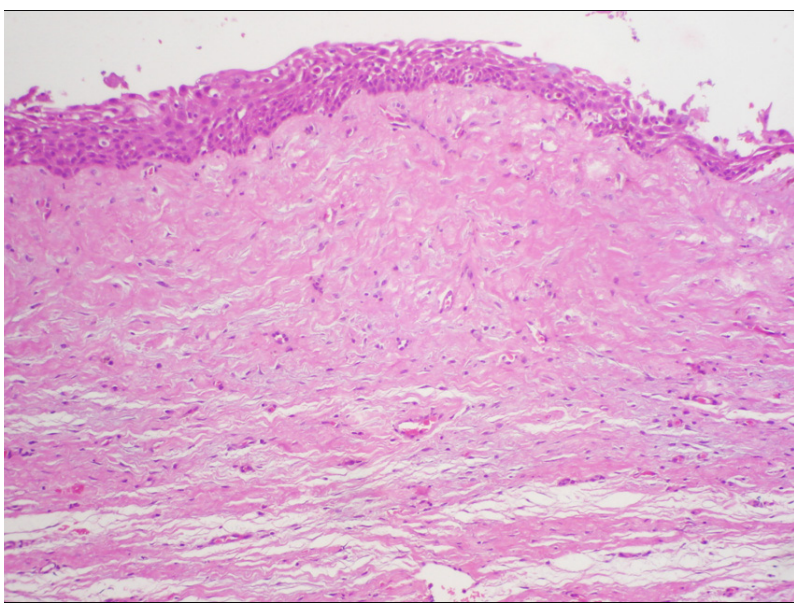

Figure 3 | Inflammatory cyst (H\&E, original magnification X100). panoramic radiograph revealed partial bone neoformation after three months (Figure 4). One year after the surgical procedure, the patient showed normal healing of the surgical wound without any sign of MRONJ (Figure 5), and she is currently under follow-up.

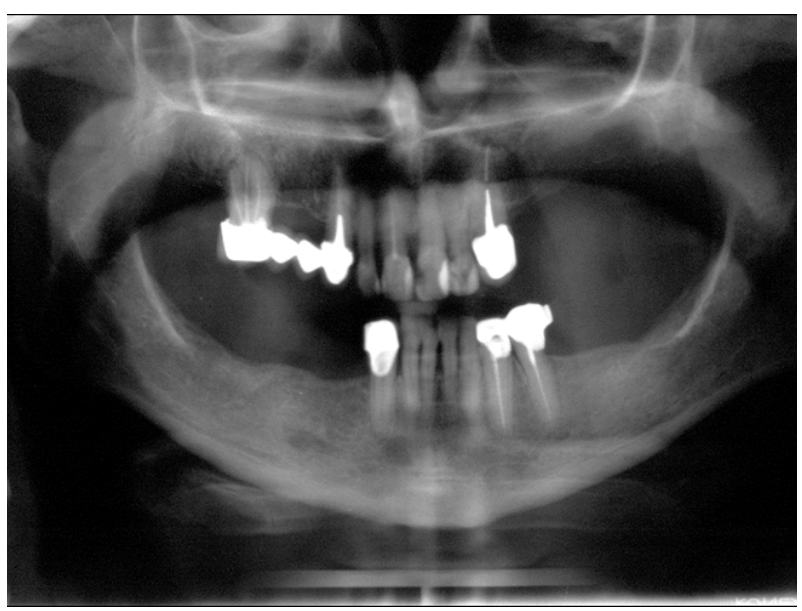

Figure 4 | Panoramic radiograph with good bone neoformation (three months after surgical procedure).

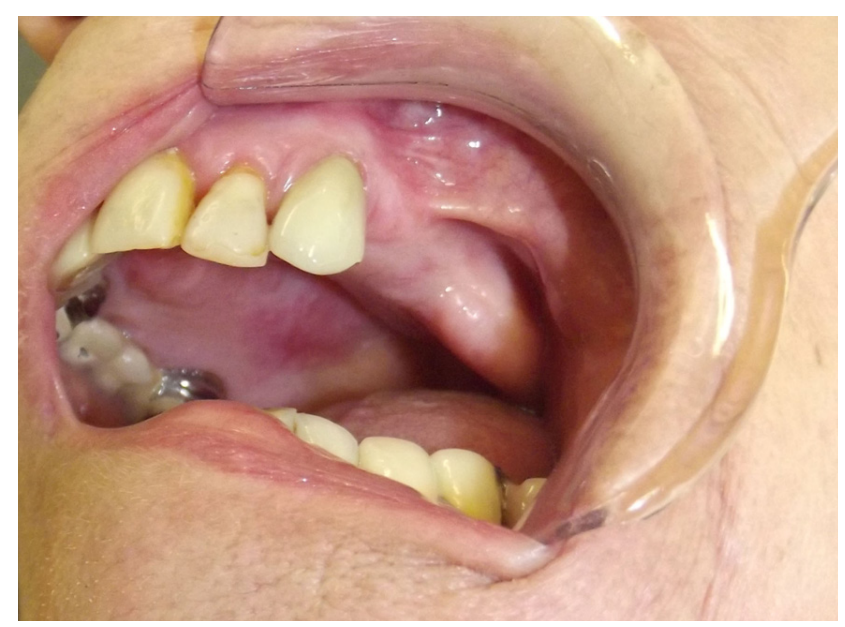

Figure 5 || Intraoral view (one year after the surgical procedure).

\section{DISCUSSION}

MRONJ is reported as an important complication of bisphosphonate therapy especially associated with the use of aminobisphosphonates, which is difficult to treat and can considerably impair the patient's quality of life. Periodontal disease, tooth extractions, dental implants placement, and periapical surgery are considered local risk factors for this condition.7 Duration of treatment, as well as bisphosphonate type and route of administration can also be included as risk factors. Although there is no scientific evidence, diabetes, obesity, coagulopathies, anemia, use of alcohol and tobacco are pointed out as possible predisposing factors.7 
Many hypotheses have been postulated to explain the pathogenesis of MRONJ. Bisphosphonates are able to interfere with remodeling of bone tissue by acting on different cells. ${ }^{8,9}$ Their effect on osteoclasts occurs by inhibiting recruitment and differentiation, decreasing life span and promoting apoptosis. The presence of numerous bacteria, especially Actinomyces sp., in MRONJ lesions has been reported. ${ }^{8}$ Other effects of these drugs, such as impairment of both angiogenesis and epithelial cell proliferation, ${ }^{9}$ support the hypothesis that osteonecrosis of the jaws has a multifactorial etiology.

Despite controversies, Ruggiero et al. ${ }^{2}$ defend that oral bisphosphonate users who need oral maxillofacial surgeries should undergo a drug holiday and bone metabolism monitoring by means of biochemical markers such as the serum CTX test. ${ }^{6}$ The American Association of Oral and Maxillofacial Surgeons (AAOMS) recommends that patients in use of oral bisphosphonates for three years or longer and using corticosteroids simultaneously should interrupt the use of bisphosphonates three months before the oral surgery, resuming the use of the drug only when the surgical wound is completely healed. ${ }^{6}$

It is important to highlight that the reported patient was successfully subjected to a surgical procedure to excise a residual cyst, even with the previous history of MRONJ. Certainly, drug interruption contributed to our successful surgery, since our patient stayed three years without alendronate use. This fact is confirmed by the CTX value, which was $20 \mathrm{pg} / \mathrm{mL}$ (high risk for MRONJ) at the time patient developed MRONJ, and had increased to $430 \mathrm{pg} / \mathrm{mL}$ (minimal risk) ${ }^{6}$ at the time surgery was performed. Hence, CTX in this case was a helpful tool for evaluating risk for MRONJ and guiding decisions in the management of patients under bisphosphonate therapy who need maxillofacial surgical interventions. ${ }^{6}$
Although bacterial infection might accelerate the development of MRONJ, it is probably not the primary etiology for the condition since MRONJ was reported spontaneously without prior bone exposure to oral microbiota. ${ }^{1}$ Nevertheless, prophylaxis protocols before dental intervention for patients at risk of developing MRONJ may have a significant beneficial effect in the prevention of secondary infection associated with MRONJ. ${ }^{2}$ Lodi et al..$^{10}$ reported minimal post operatory complications associated with 38 dental extractions in 23 patients receiving bisphosphonate therapy and treated with amoxicillin (1 g, 3 times/day) 1 day before dental intervention and continued for 17 days. Although there is no consensus in the literature about this protocol, penicillin is the antibiotic of choice for prophylactic and post operatory use in oral surgery in patients at risk of developing MRONJ. ${ }^{6,10}$ In this case it was not prescribed amoxicillin before the surgical procedure.

We have reported here a well-succeeded surgical excision of a residual cyst in a patient who had previously developed MRONJ associated with sodium alendronate use. Despite the evidence of the risks, maxillofacial surgeries are often demanded by patients under bisphosphonate therapy. Moreover, although rare, MRONJ associated with oral bisphosphonate does happen. Therefore, the correct approaching of the patient can provide a safe procedure avoiding MRONJ occurrence. Also, the need for identifying treatment protocols capable of reducing the incidence of this oral disease is ever more pressing.

\section{REFERENCES}

1. Ruggiero SL, Dodson TB, Assael LA, Landesberg R, Marx RE, Mehrotra B. American Association of Oral and Maxillofacial Surgeons position paper on bisphosphonate-related osteonecrosis of the jaw - 2009 update. Aust Endod J. 2009 Dec;35(3):119-130. doi: 10.1016/j.joms.2009.01.009.

2. Ruggiero SL, Dodson TB, Fantasia J, Goodday R, Aghaloo T, Mehrotra B et al. American Association of Oral and 
Maxillofacial Surgeons position paper on medicationrelated osteonecrosis of the jaw - 2014 update. J Oral Maxillofac Surg. 2014 Oct;72(10):1938-56. doi: 10.1016/j. joms.2014.04.031.

3. Khosla S, Burr D, Cauley J, Dempster DW, Ebeling PR, Felsenberg D, et al. Bisphosphonate-associated osteonecrosis of the jaw: report of a task force of the American Society for Bone and Mineral Research. J Bone Miner Res. 2007 Oct;22(10):1479-91. doi: 10.1359/jbmr.0707onj.

4. Ruggiero SL, Fantasia J, Carlson E. Bisphosphonate-related osteonecrosis of the jaw: background and guidelines for diagnosis, staging and management. Oral Surg Oral Med Oral Pathol Oral Radiol Endod. 2006 Oct;102(4):433-41. doi: 10.1016/j.tripleo.2006.06.004.

5. Hansen T, Kirkpatrick CJ, Walter C, Kunkel M. Increased numbers of osteoclasts expressing cysteine proteinase cathepsin $\mathrm{K}$ in patients with infected osteoradionecrosis and bisphosphonate-associated osteonecrosis - a paradoxical observation? Virchows Arch. 2006 Oct;449(4):448-54. doi: 10.1007/s00428-006-0261-y.

6. Marx RE. Reconstruction of defects caused by bisphosphonate-induced osteonecrosis of the jaws. J Oral Maxillofac Surg. 2009 May;67(5 Suppl):107-19. doi: 10.1016/j. joms.2008.12.007.
7. Cavanna L, Berte R, Arcari A, Mordenti P, Pagani R, Vallisa D. Osteonecrosis of the jaw. A newly emerging site-specific osseous pathology in patients with cancer treated with bisphosphonates. Report of five cases and review of the literature. Eur J Intern Med. 2007 Sep;18(5):417-22. doi: 10.1016/j. ejim.2006.10.008.

8. Allen MR, Burr DB. Mandible matrix necrosis in beagle dogs after 3 years of daily oral bisphosphonate treatment. J Oral Maxillofac Surg. 2008 May;66(5):987-94. doi:10.1016/j. joms.2008.01.038.

9. Vasconcelos AC, Berti-Couto SA, Azambuja AA, Salum FG, Figueiredo MA, da Silva VD, et al. Comparison of effects of clodronate and zoledronic acid on the repair of maxilla surgical wounds - histomorphometric, receptor activator of nuclear factor-kB ligand, osteoprotegerin, von Willebrand factor, and caspase-3 evaluation. J Oral Pathol Med. 2012 Oct;41(9):702-12. doi: 10.1111/j.16oo0714.2012.01140.x.

10. Lodi G, Sardella A, Salis A, Demarosi F, Tarozzi M, Carrassi A. Tooth extraction in patients taking intravenous bisphosphonates: a preventive protocol and case series. J Oral Maxillofac Surg. 2010 Jan;68(1):107-10. doi: 10.1016/j. joms.2009.07.068. 